\title{
2,3,5,6-Tetramethylpyrazine (TMP) down-regulated arsenic-induced heme oxygenase-1 and ARS2 expression by inhibiting Nrf2, NF- $к$ B, AP-1 and MAPK pathways in human proximal tubular cells
}

\author{
Xuezhong Gong ${ }^{1,2} \cdot$ Vladimir N. Ivanov ${ }^{2}$ Tom K. Hei ${ }^{2,3}$
}

Received: 26 May 2015 / Accepted: 10 September 2015 / Published online: 24 September 2015

(C) Springer-Verlag Berlin Heidelberg 2015

\begin{abstract}
Our recent study demonstrated that sodium arsenite at a clinically relevant dose induced nephrotoxicity in human renal proximal tubular epithelial cell line HK-2, which could be inhibited by natural product 2,3,5,6-tetramethylpyrazine (TMP) with antioxidant activity. The present study demonstrated that arsenic exposure resulted in protein and enzymatic induction of heme oxygenase-1 (HO-1) in dose- and time-dependent manners in HK-2 cells. Blocking HO-1 enzymatic activity by zinc protoporphyrin (ZnPP) augmented arsenic-induced apoptosis, ROS production and mitochondrial dysfunction, suggesting a critical role for HO-1 as a renal protectant in this procession. On the other hand, TMP, upstream of HO-1, inhibited arsenic-induced ROS production and ROS-dependent HO-1 expression. TMP also prevented mitochondria dysfunction and suppressed activation of the intrinsic apoptotic pathway in HK-2 cells. Our results revealed that the regulation of arsenic-induced HO-1 expression was performed through multiple ROS-dependent signal pathways and the corresponding transcription factors, including p38 MAPK and JNK (but not ERK), AP-1, Nrf2 and NF-кB. TMP inhibited arsenic-induced activations of JNK, p38 MAPK,
\end{abstract}

Xuezhong Gong

shnanshan@hotmail.com

1 Department of Nephrology, Shanghai Municipal Hospital of Traditional Chinese Medicine, Shanghai University of Traditional Chinese Medicine, 274 Zhijiang Middle Road, Shanghai 200071, China

2 Center for Radiological Research, College of Physician and Surgeons, Columbia University, 630 West 168th Street, New York, NY 10032, USA

3 Department of Radiation Oncology, College of Physician and Surgeons, Columbia University, 630 West 168th Street, New York, NY 10032, USA
ERK, AP-1 and Nrf2 and block HO-1 protein expression. The present study, furthermore, demonstrated arsenicinduced expression of arsenic response protein 2 (ARS2) that was regulated by $\mathrm{p} 38$ MAPK, ERK and NF-кB. To our knowledge, this is the first report showing that ARS2 involved in arsenic-induced nephrotoxicity, while TMP pretreatment prevented such an up-regulation of ARS2 in HK-2 cells. Given ARS2 and HO-1 sharing the similar regulation mechanism, we speculated that ARS2 might also mediate cell survival in this procession. In summary, our study highlighted a role of $\mathrm{HO}-1$ in the protection against arsenic-induced cytotoxicity downstream from the primary targets of TMP and further indicated that TMP may be used as a potential therapeutic agent in the treatment of arsenicinduced nephrotoxicity.

Keywords Sodium arsenite - Tetramethylpyrazine (TMP) · Nephrotoxicity · Mitochondrial dysfunction · Inducible heme oxygenase-1 (HO-1) · Arsenic response protein 2 (ARS2) - Nuclear factor erythroid derived-2 (Nrf2)

$\begin{array}{ll}\text { Abbreviations } \\ \text { AG } & \text { Aminoguanidine } \\ \text { AKI } & \text { Acute kidney injury } \\ \text { ARS2 } & \text { Arsenic response protein } 2 \\ \text { As } & \text { Arsenic } \\ \text { Bay } & \text { Bay 11-7082 } \\ \text { CKD } & \text { Chronic kidney disease } \\ \text { DHE } & \text { Dihydroethidium } \\ \text { FACS } & \text { Fluorescence-activated cell sorter } \\ \text { HO-1 } & \text { Heme oxygenase-1 } \\ \text { MAPK } & \text { Mitogen-activated protein kinase } \\ \text { Nrf2 } & \text { Nuclear factor erythroid derived-2 } \\ \text { NAC } & N \text {-acetylcysteine }\end{array}$

\section{Abbreviations}

AG Aminoguanidine

AKI Acute kidney injury

ARS2 Arsenic response protein 2

As Arsenic

Bay Bay 11-7082

CKD Chronic kidney disease

DHE Dihydroethidium

FACS Fluorescence-activated cell sorter

HO-1 Heme oxygenase-1

MAPK Mitogen-activated protein kinase

NAC $N$-acetylcysteine 


$\begin{array}{ll}\text { NF- } \kappa \text { B } & \text { Nuclear factor- } \mathrm{k} \text { B } \\ \text { PARP } & \text { Poly ADP-ribose polymerase } \\ \text { PI } & \text { Propidium iodide } \\ \text { ROS } & \text { Reactive oxygen species } \\ \text { SB } & \text { SB203580 } \\ \text { SDH } & \text { Sucinate dehydrogenase } \\ \text { SP } & \text { SP600125 } \\ \text { TMP } & \text { Tetramethylpyrazine } \\ \text { TUNEL } & \text { Terminal deoxynucleotidyl transferase-mediated } \\ & \text { dUTP-biotin nick end labeling } \\ \text { U0 } & \text { U0126 } \\ \text { ZnPP } & \text { Zinc protoporphyrin }\end{array}$

\section{Introduction}

Arsenic (As) is an important environmental contaminant affecting more than 140 million people worldwide through contaminated drinking water (Rodriguez-Lado et al. 2013). Recent epidemiologic studies in a rural US population, in some regions of China and especially in Bangladesh suggest arsenic is a major risk factor for kidney disease (Chen et al. 2011; Zheng et al. 2013). Kidney is one of the targeted organs of arsenic cytotoxicity that could cause renal dysfunction, proteinuria and chronic kidney disease (CKD) (Yu et al. 2013; Michael 2013; Ruiz-Hernandez et al. 2015; Zheng et al. 2014; Chen et al. 2014). Our recent study demonstrated that sodium arsenite at a clinically relevant dose induced cytotoxicity in human renal proximal tubular epithelial cell line, HK-2, which served as a representative cell model for exposures of the human kidney to As, drug-induced nephrotoxicity and acute kidney injury (Huang et al. 2015; Peraza et al. 2003, 2006; Wang et al. 2013b). Furthermore, our recent results indicated that such a nephrotoxicity was associated with a dramatic increase in intracellular ROS production, mitochondrial dysfunction, inflammation, apoptosis and autophagy (Gong et al. 2014). However, the precise molecular mechanisms responsible for arsenic nephrotoxicity remain largely unclear.

The inducible heme oxygenase-1 (HO-1) could exhibit anti-apoptotic, anti-oxidative and anti-inflammatory properties and thus be a renal protectant in multiple kidney injuries, such as acute kidney injury (AKI) induced by ischemia or nephrotoxicity induced by cisplatin and contrasting solutions (Chang et al. 2014; Miyagi et al. 2014). The critical role of HO-1 has also been reported in several organ injuries (Wang and Dore 2007; Billings et al. 2014). Given that HO-1 also has been identified as a response biomarker for arsenic exposure in various types of cells, we were very interested: (1) What is the role of HO-1 in As-induced nephrotoxicity (Gong et al. 2014) at clinically relevant doses? (2) What are the intricate molecular mechanisms involving in the regulation of HO-1 induction during As nephrotoxicity?

Furthermore, we have previously identified 2,3,5,6-tetramethylpyrazine (TMP), a compound extracted from the Chinese medicinal plant Ligusticum wallichi (Chuanxiong) as a protective agent against arsenic nephrotoxicity, which could attenuate ROS production, inflammation and cell death (Gong et al. 2014). One of the main aims of the current study was to further elucidate a potential relationship between HO-1 production and the renal protection by antioxidant TMP in arsenic nephrotoxicity, which is not well understood.

Arsenic response protein 2 (ARS2, also known as Srrt) was first isolated as a gene product conferring resistance to arsenite and arsenate in Ass/S5 cell line (Rossman and Wang 1999). Based on the very limited published data, ARS2 has been shown to be essential for the development of plants and mammals and also acts as a transcriptional regulator of Sox 2 in neural stem cell (Kiriyama et al. 2009; Wilson et al. 2008; Andreu-Agullo et al. 2012). However, the precise biological functions of ARS2 in mammalian are largely unknown (Wilson et al. 2008; Andreu-Agullo et al. 2012). The previous work from our laboratory has shown an up-regulation of ARS2 expression in human neural stem cell after arsenic exposure (Ivanov and Hei 2013), which suggested that ARS2 might be involved in arsenic-induced cytotoxicity and supported the previous suggestion that ARS2 has essential functions (Wilson et al. 2008). However, the signaling mechanism regulating ARS2 induction is still unclear, and a role of ARS2 in arsenic nephrotoxicity has not been reported so far.

In the present study, we have further investigated the potential relationships between HO-1 induction, TMPmediated renal protection and ARS2 expression in the suppression of arsenic nephrotoxicity.

\section{Materials}

All chemicals were purchased from Sigma (St. Louis, MO, USA) unless otherwise stated. NF- $\kappa$ B inhibitor Bay 11-7082 (Bay), MAPK p38 inhibitor SB203580 (SB) and ERK inhibitor U0126 (U0) were obtained from Calbiochem (La Jolla, CA, USA), and JNK inhibitor SP600125 (SP) was obtained from Biomol (Plymouth Meeting, PA, USA).

\section{Cell culture and treatment}

The human proximal tubular cell line HK-2 (American Type Culture Collection, Manassas, VA, USA) was grown in culture medium (keratinocyte serum-free 
medium $+5 \mathrm{ng} / \mathrm{ml}$ epidermal growth factor and $50 \mu \mathrm{g} /$ $\mathrm{ml}$ bovine extract $+100 \mathrm{U} / \mathrm{ml}$ penicillin and $100 \mu \mathrm{g} /$ $\mathrm{ml}$ of streptomycin) at $37{ }^{\circ} \mathrm{C}$ and $5 \% \mathrm{CO}_{2}$ humidified environment.

The next stock solutions were prepared: $50 \mathrm{mM}$ sodium arsenite, antioxidant $\mathrm{N}$-acetylcysteine (NAC, $10 \mathrm{mM}$ ), TMP $(50 \mu \mathrm{M}, 100 \mu \mathrm{M})$ in PBS, NF- $\mathrm{BB}$ inhibitor Bay $(5 \mu \mathrm{M})$, MAPK p38 inhibitor SB $(10 \mu \mathrm{M})$, ERK inhibitor U0 $(10 \mu \mathrm{M})$ and JNK inhibitor SP $(10 \mu \mathrm{M})$ in DMSO, and HO-1 inhibitor zinc protoporphyrin (ZnPP, $2 \mu \mathrm{M})$ in methanol. NAC, TMP and other inhibitors were added into media 30 min before As.

\section{Intracellular ROS detection}

Dihydroethidium (DHE, Invitrogen, Eugene, OR) method to detect intracellular superoxide production was used. After 24-h As treatment, cells were exposed to $2 \mu \mathrm{M}$ DHE $45 \mathrm{~min}$ at $37{ }^{\circ} \mathrm{C}$ in the dark and then washed twice with PBS. Finally, fluorescence-activated cell sorter (FACS) analysis was performed (Becton-Dickinson, Franklin Lakes, NJ) using the CellQuest program. Samples were analyzed in triplicate, and all experiments were repeated three times independently.

\section{Analyses of apoptosis by PI staining and FACS assay and TUNEL staining}

Apoptotic cells were identified by diminished DNA content in the sub-G1 population of normal diploid cells by FACS assay after staining with propidium iodide (PI) (Gong et al. 2010). Approximately 20,000 counts were made for each sample. Finally, the data were collected and analyzed with CellQuest program combined with FACS machine. Apoptotic levels were calculated by evaluating the percentage of events accumulated in the sub-G1 position. Samples were analyzed in triplicate and repeated 3 times.

To further confirm apoptotic cell death, terminal deoxynucleotidyl transferase-mediated dUTP-biotin nick end labeling (TUNEL) staining was performed using a ClickiT TUNEL Alexa Fluor 488 Imaging Assay (Invitrogen, Grand Island, NY) according to the manufacturer's instructions except that PI replaced Hoechst 33342 to mount cells and label all nuclei. Stained nuclei were analyzed by a Nikon confocal microscope (Nikon TE200-C1) at $24{ }^{\circ} \mathrm{C}$ room temperature. TUNEL-positive cell numbers from 20 different fields (a total of 2000-2500 cells) were counted to get an average number of cells per field.

\section{Mitochondrial network morphology assay}

Mitochondrial network morphology and activity were visualized by using MitoTracker Green (Molecular Probes,
Invitrogen). In brief, cells were grown on 6-well plate and incubated with $200 \mathrm{nM}$ MitoTracker Green for another 20 min at $37{ }^{\circ} \mathrm{C}$ after 6-h As treatment. After three-time washes with PBS, cells were fixed with $4 \%$ paraformaldehyde. Confocal fluorescence microscopy images were captured, and mitochondrial network morphology (tubular and non-tubular) was quantified by Image $\mathbf{J}$ software (NIH). Each treatment was randomly selected 20 noncontiguous fields for further observation and analysis, generally, each field containing 20-25 cells with mitochondrial networks. Percentages of normal (tubular) and abnormal (non-tubular) mitochondrial network morphologies were counted.

\section{Mitochondrial function assay: cytochrome c oxidase (Cox) and succinate dehydrogenase (SDH) histochemistry}

Cox and SDH histochemistry were monitored as described previously (Gong et al. 2014). In brief, cells were cultured on glass cover inside a 6-well plate. After $6 \mathrm{~h}$ indicated treatment, cells on glass cover were allowed to dry at room temperature for $1 \mathrm{~h}$ and then followed by $15-\mathrm{min}$ preincubation at room temperature with $1 \mathrm{mM} \mathrm{CoCl}_{2}$ and $50 \mu \mathrm{l}$ DMSO in $50 \mathrm{mM}$ Tris- $\mathrm{HCl}, \mathrm{pH} \mathrm{7.6,} \mathrm{containing}$ $10 \%$ sucrose. All samples were rinsed once in PBS and incubated for another $3 \mathrm{~h}$ with incubation medium $(10 \mathrm{mg}$ cytochrome $c, 10 \mathrm{mg}$ of DAB hydrochloride, $2 \mathrm{mg}$ of catalase and $25 \mu \mathrm{l}$ DMSO resolved in $10 \mathrm{ml} 0.1 \mathrm{M}$ phosphate buffer, $\mathrm{pH}$ 7.6). After further three-time rinse, all samples were mounted on warm glycerin gelatin and observed under Nikon LABOPHOT-2 microscope to capture images with SPOT Basic TM software. Quantification of histochemical staining was performed with Image $\mathbf{J}$ software (NIH). Camera light settings were standardized, and color images were captured with $40 \times$ objective.

\section{Western blotting}

After the various treatments, whole cell lysates were prepared by incubation in RIPA buffer (Invitrogen). For nuclear transcription factor Nrf2 immunoblotting analysis, nuclear extracts were prepared using methods described previously (Schreiber et al. 1989). Protein concentrations were determined with Bio-Rad DC protein assay (Bio-Rad Laboratories, Calif., USA) using bovine serum albumin as the standard. The resulting protein samples underwent SDS-PAGE gel electrophoresis and were transferred to PVDF membrane.

The specific primary antibodies included the following rabbit Abs: anti-HO-1 (Enzo Life Sciences), anti-Bcl-xl (Cell Signaling), anti-Bax (Cell Signaling), anti-PARP (Cell Signaling), anti-pro-caspase-9 (Cell 
Signaling), anti-Nrf2 (Cell Signaling), anti-JNK (Cell Signaling), anti-phospho-JNK (Cell Signaling), antiERK (Cell Signaling), anti-phospho-ERK (Cell Signaling), anti-p38 MAPK (Cell Signaling), anti-phospho-p38 MAPK (Cell Signaling), anti-ARS2 (Santa Cruz), antihistone H3 (Cell signaling) and mouse anti-beta actin (Sigma).

\section{Statistical analysis}

The data were presented as mean \pm SD for a minimum of three independent experiments. All comparisons were made using either one-way ANOVA or a two-tailed $t$ test analysis depending on how many conditions were compared in each experiment. One-way ANOVA was followed by Tukey's post hoc test. A value of $\mathrm{p}<0.05$ was considered significant.

(a)

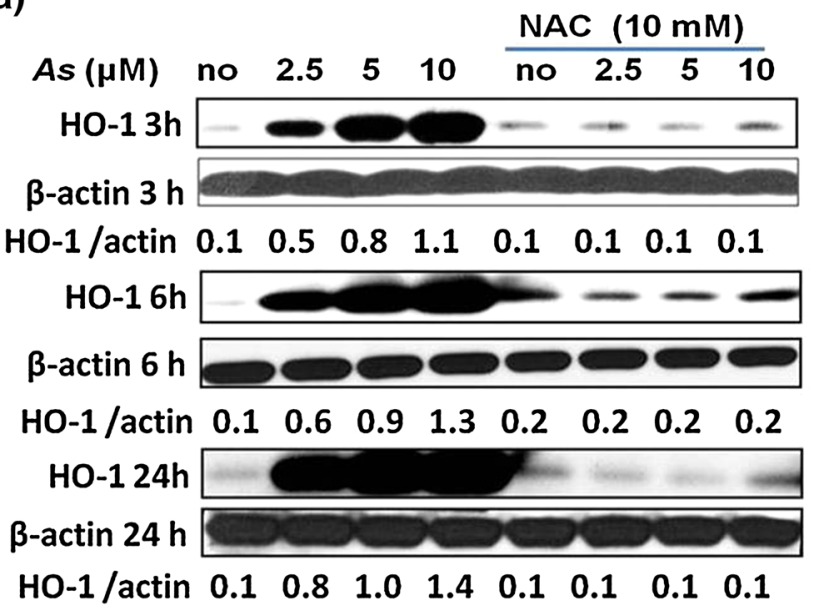

\section{Results}

\section{2,3,5,6-Tetramethylpyrazine (TMP) inhibited arsenic-induced ROS-dependent HO-1 expression}

Arsenic (As) has been identified as inducer of heme oxygenase-1 (HO-1) expression in many cells and tissues (Teng et al. 2013; Li et al. 2013). Consistent with these reports, we demonstrated that the induction of HO-1 protein expression was dose and time dependent in HK-2 cells after As exposure. Since the As dose range of 2.0-10 $\mu \mathrm{M}$ is successfully applied for treating acute promyelocytic leukemia (APL) and multiple myelomas (Ivanov and Hei 2004, 2005; Shen et al. 1997), we therefore choose this dose range for our present study. Furthermore, antioxidants $\mathrm{N}$-acetylcysteine (NAC) and TMP significantly inhibited arsenic-induced HO-1 expression (Fig. 1a, b). In contrast,

(b)

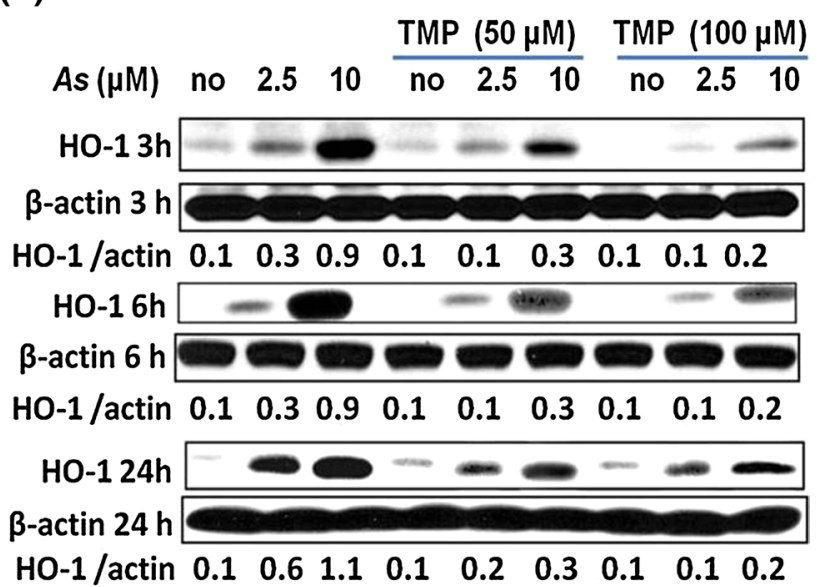

(c)

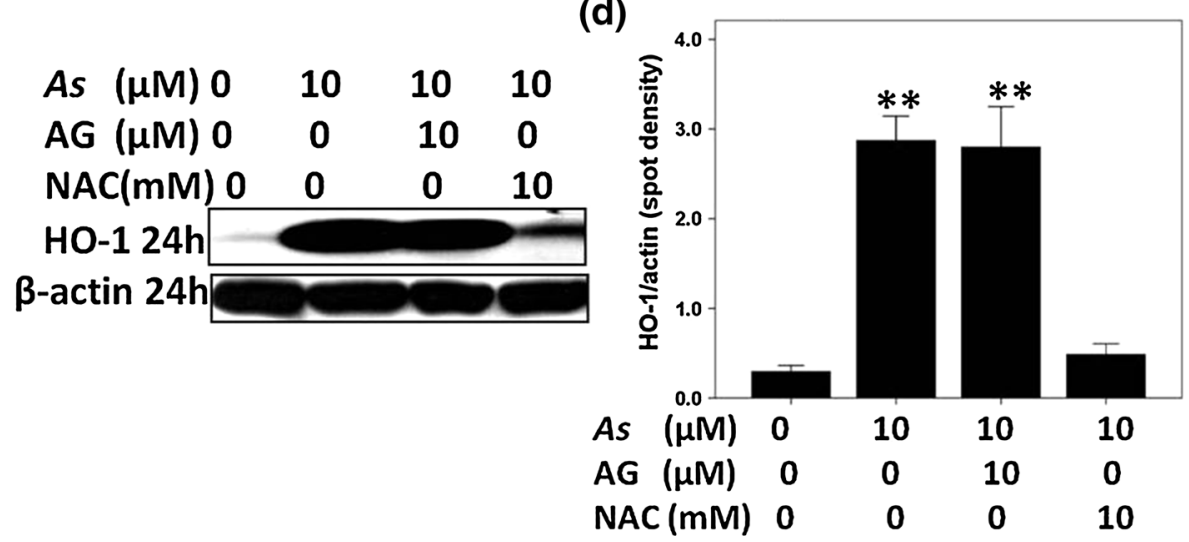

Fig. 1 TMP inhibited arsenic-induced ROS-dependent HO-1 expression in HK-2 cells. a, b HK-2 cells were exposed to sodium arsenite at indicated doses for 3, 6 and $24 \mathrm{~h}$ alone or in a combination with either $10 \mathrm{mM}$ NAC or $50-100 \mu \mathrm{M}$ TMP. Arsenite $(A s)$ exposure induced HO- 1 protein expression in a dose- and time-dependent manner, whereas NAC and TMP pretreatment sufficiently blocked HO-1 up-regulation. c, d Compared with $10 \mathrm{mM}$ NAC, $10 \mu \mathrm{M}$ AG, the inhibitor of iNOS, failed in preventing HO-1 up-regulation. $\beta$-actin was used as loading control. Quantitative densitometry of protein bands was performed. Values are mean $\pm \mathrm{SD}(n=3),(* *) p<0.01$ versus control 
aminoguanidine (AG), the iNOS inhibitor, failed in preventing HO-1 up-regulation (Fig. 1c, d).

\section{Blocking HO-1 with ZnPP augmented As-induced apoptosis and ROS production}

To verify the role of HO-1 in arsenic (As) nephrotoxicity, zinc protoporphyrin ( $\mathrm{ZnPP})$, a known inhibitor of HO-1 enzymatic activity, was used. Interestingly, $\mathrm{ZnPP}$ aggravated sodium arsenite $(10 \mu \mathrm{M})$-induced cytotoxicity and apoptosis that was confirmed by increased percentage of cells accumulated in the sub-G1 position (35.7 vs. $12.5 \%$ ) determined by FACS analysis of PI-stained cell nuclei (Fig. 2a, b) and by \% TUNEL-positive staining cells (Fig. 2c, d).

Several studies have shown that the induction of HO-1 by As is ROS dependent (Fan et al. 2010; Teng et al. 2013). Our previous data have demonstrated that As exposure elevated ROS production in HK-2 cells (Gong et al. 2014). The present results demonstrate that ROS production is upregulated by 2.19 -fold with $10 \mu \mathrm{M}$ sodium arsenite treatment. Furthermore, combined treatments with $\mathrm{ZnPP}$ and $10 \mu \mathrm{M}$ sodium arsenite resulted in a 5.35 -fold increase in ROS production highlighting antioxidant role of HO-1 activation (Fig. 2e, f). (a)

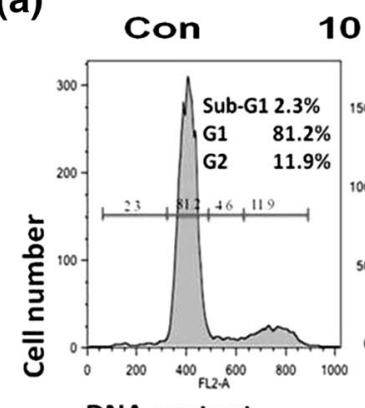

$10(\mu \mathrm{M})$ As

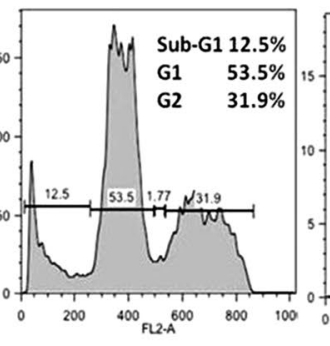

$10(\mu \mathrm{M}) A s+Z n P P$

(c)

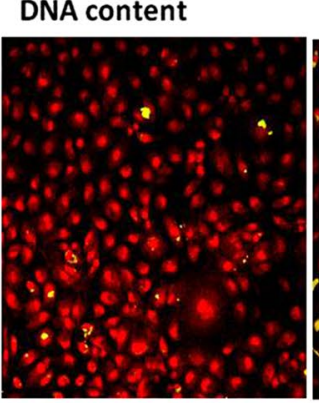

(e)
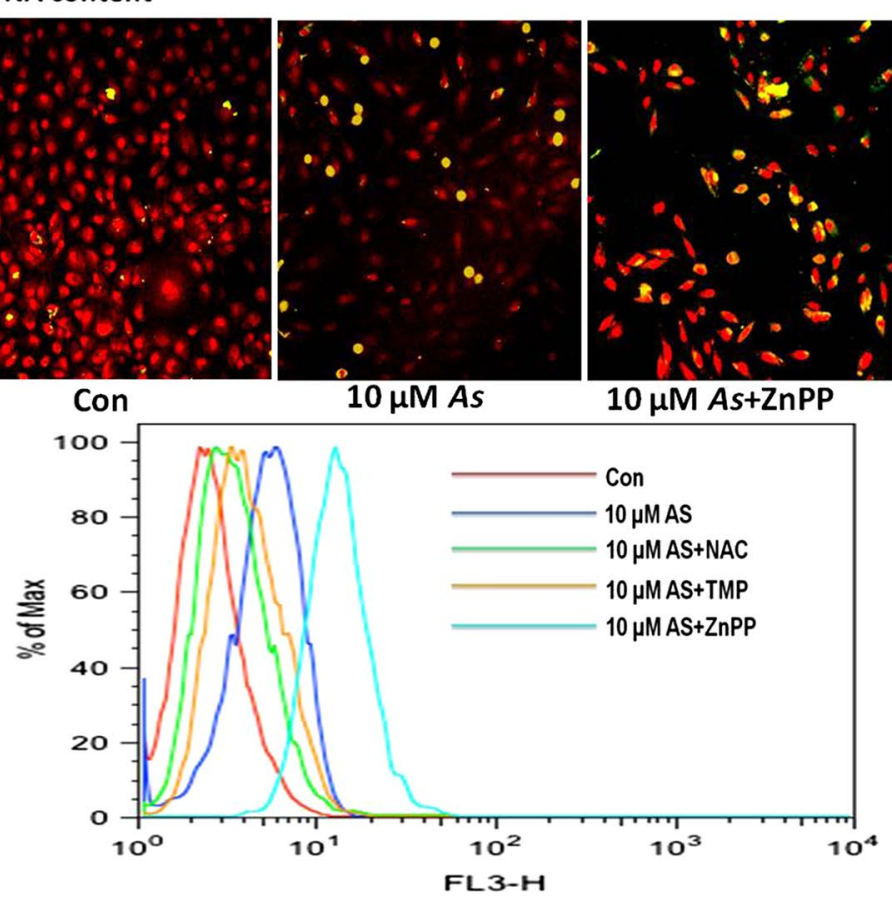

(b)

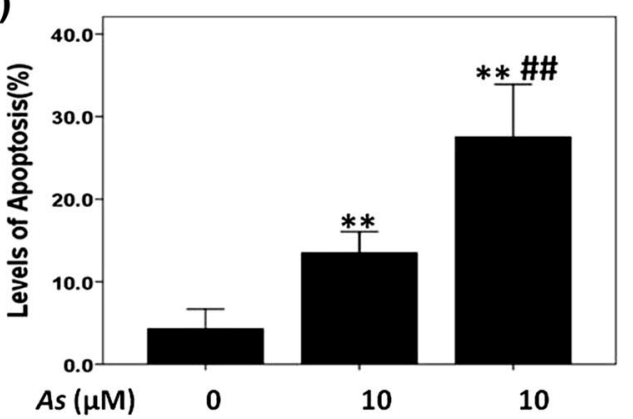

(d)

(f)
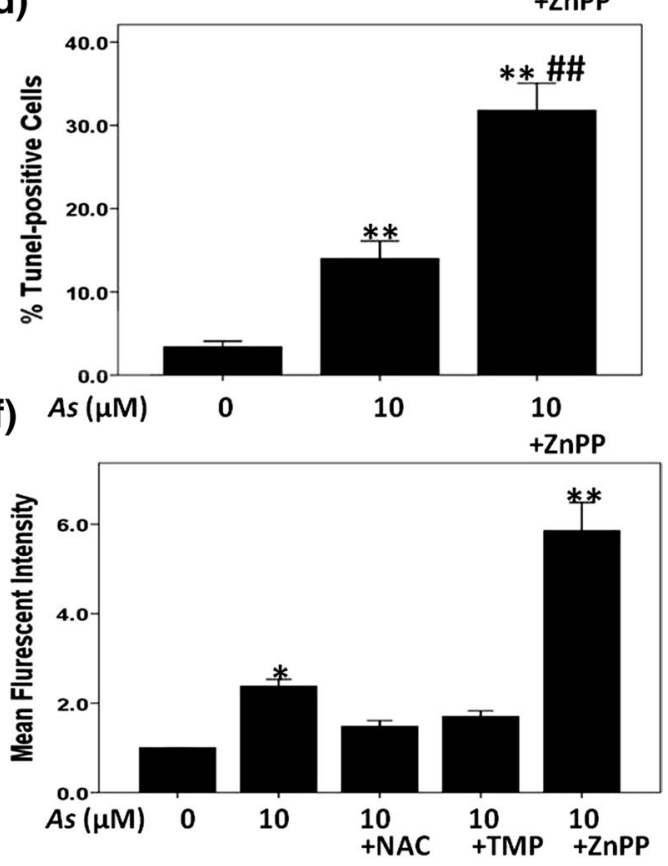

Fig. 2 Blocking HO-1 activity with ZnPP augmented arsenicinduced apoptosis and ROS production. Apoptosis levels and intracellular ROS production were measured $24 \mathrm{~h}$ after arsenic $(A s)$ treatment with or without $2 \mu \mathrm{M}$ ZnPP pretreatment of HK-2 cells. a, b Levels of apoptosis were calculated by evaluating the percentage of cells accumulated in the sub-G1 position after PI staining DNA. c, d Apoptosis was determined by TUNEL staining, and average percentages of TUNEL-positive cells were assessed in each group. $\mathbf{e}, \mathbf{f}$ $100 \mu \mathrm{M}$ TMP and $10 \mathrm{mM}$ NAC inhibited As-induced ROS generation at $24 \mathrm{~h}$, while $2 \mu \mathrm{M} \mathrm{ZnPP}$ augmented ROS generation. Values are mean $\pm \mathrm{SD}(n=3),(*) p<0.05$ versus $\mathrm{Con} ;\left({ }^{*}\right) p<0.01$ versus Con; $\left({ }^{\# \#)} p<0.01\right.$ versus $10 \mu \mathrm{M}$ As 


\section{Inhibition of HO-1 activity with ZnPP augmented As-induced mitochondrial dysfunction}

To further investigate the relationships among mitochondrial alterations, As nephrotoxicity, and blocking HO-1 activity, mitochondrial morphology was analyzed at the single cell level in Mito Tracker Green-stained HK2 cells. As shown in Fig. 3a, a large number of cells (84.6\%) presented a normal (tubular) shape of mitochondrial network in the control group, while a number of cells with the abnormal (elongated or fragmented) mitochondrial networks were obviously increased in $10 \mu \mathrm{M}$ sodium arsenite-treated group; accordingly, the percentage of cells with tubular mitochondria in this group dropped to $35.7 \%$. Augmented mitochondrial morphology changes were observed in $\mathrm{ZnPP}$ pretreatment group, whereas TMP and NAC pretreatment can effectively prevent this change in mitochondrial network morphology, and percentages of normal tubular morphology were 33.5, 72.5 and $69.8 \%$ (Fig. 3b).

Our previous study (Gong et al. 2014) indicated that sodium arsenite induced mitochondrial dysfunction in HK-2 cells, shown as strong loss of mitochondrial membrane potential and decreased Cox enzyme activity, which could be inhibited by NAC and TMP. In the present study, results of Cox enzyme histochemistry and mitochondrial membrane potential assay (data not shown) indicated that blocking HO-1 activity with ZnPP aggravated such a mitochondria dysfunction. Interestingly, the enzyme activity of $\mathrm{SDH}$, or Complex II, encoded entirely by nuclear genome, was not significantly impaired by sodium arsenite treatment or ZnPP (Fig. 3c-e). (a)
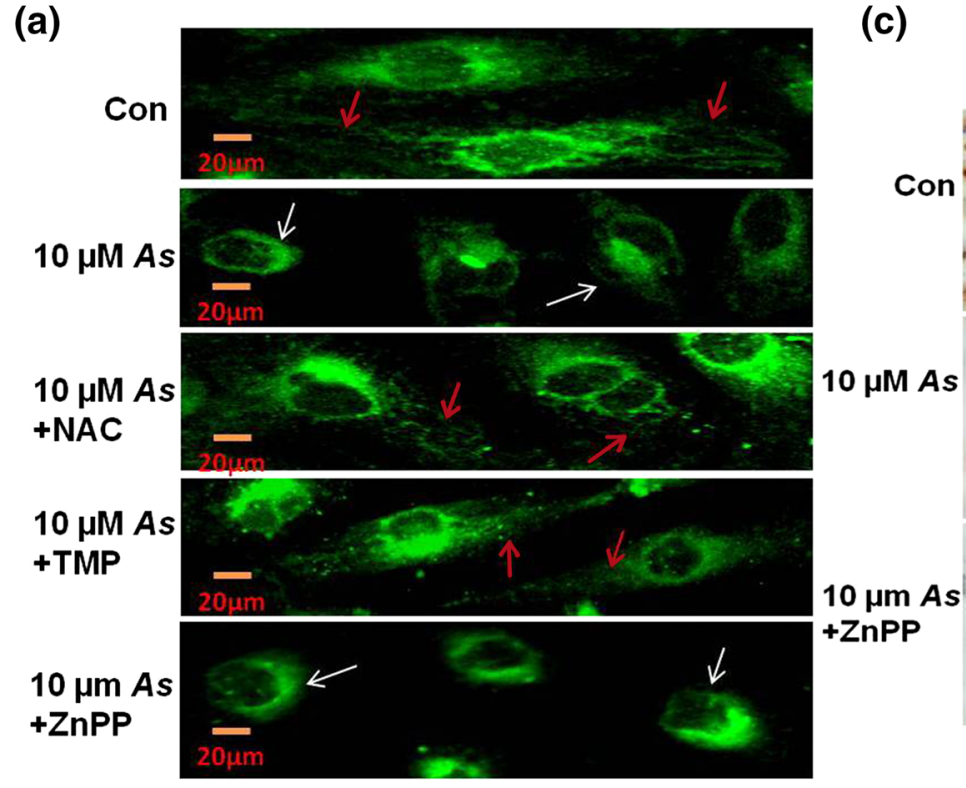

(b)

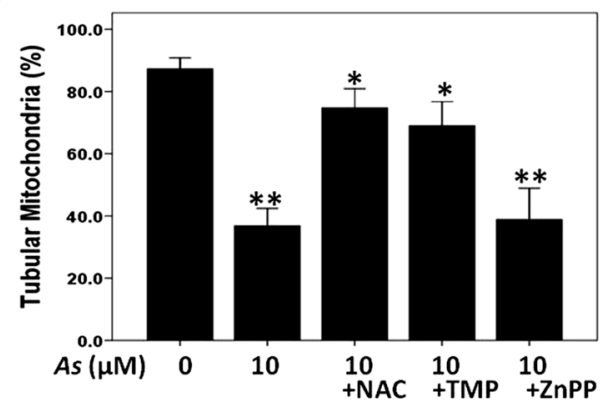

(d)

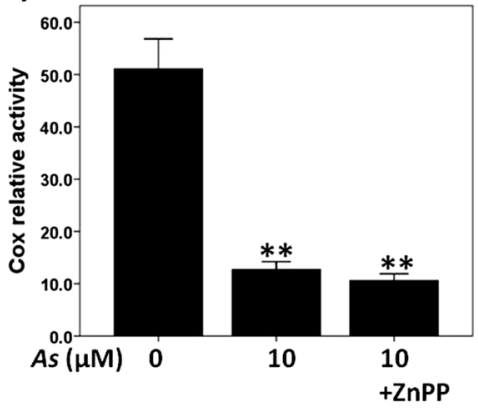

(c)

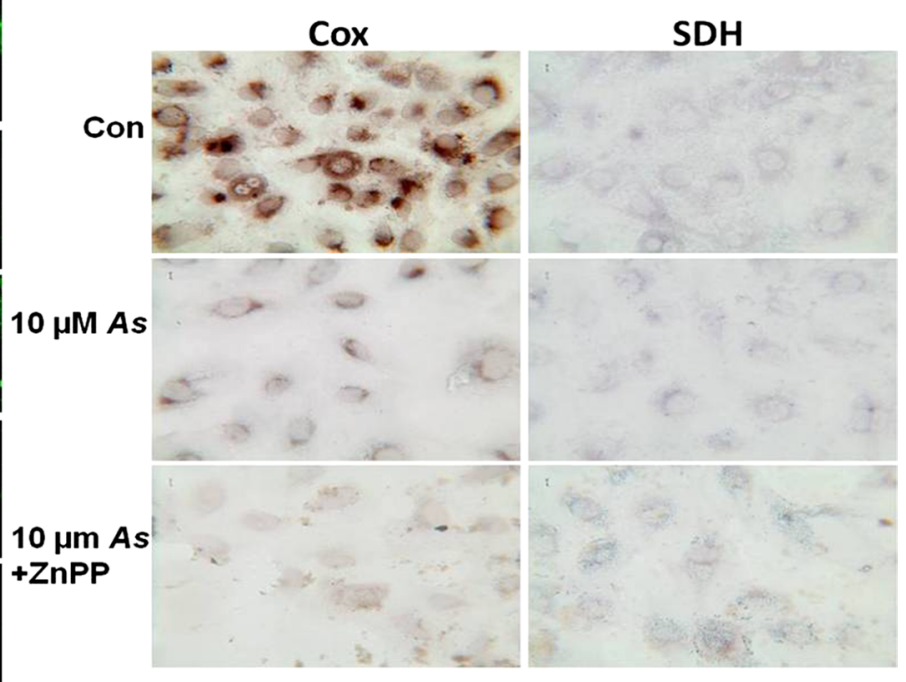

(e)

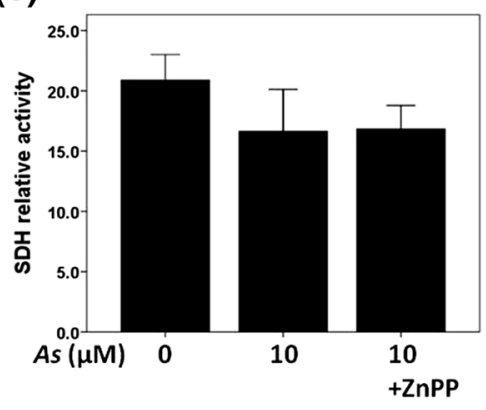

Fig. 3 Blocking HO-1 with ZnPP augmented arsenic-induced mitochondrial dysfunction. a, b Mitochondrial morphology was determined at the single cell level in MitoTracker Green-stained HK2 cells, and the cell number with different mitochondrial morphology (normal as tubular with thick arrow, elongated or fragmented with thin arrow) was counted in each group. c, d As-induced mitochondrial dysfunction was verified by a decreased cytochrome $c$ oxidase (Cox) histochemical staining. c, e Succinate dehydrogenase $(S D H)$ histochemical staining. Values are mean $\pm \mathrm{SD}(n=3),(*) p<0.05$ versus Con, $(* *) p<0.01$ versus Con 
TMP prevented As-triggered the intrinsic apoptotic pathway activation in $\mathrm{HK}-2$ cells

To explore whether sodium arsenite-induced apoptosis in HK-2 cells used the intrinsic mitochondrial pathway, the protein levels of Bax and Bcl-xl, a pro-apoptotic and an anti-apoptotic member, respectively, of the Bcl-2 family, were analyzed by Western blotting. Sodium arsenite treatment for $24 \mathrm{~h}$ resulted in a reduction of anti-apoptotic Bcl$\mathrm{xl}$ protein expression and an increase in the pro-apoptotic Bax protein expression (Fig. 4a). The decrease in pro-caspase-9 protein levels (that indicated on caspase- 9 activation) and caspase-9/caspase-3-dependent PARP1 cleavage induced by sodium arsenite treatment further demonstrated the involvement of intrinsic apoptotic pathway (Fig. 4a). Co-treatment with TMP (50 and $100 \mu \mathrm{M}$ ) prevented arsenic-triggered the intrinsic apoptotic pathway activation, and $100 \mu \mathrm{M}$ TMP showed higher protective efficiency (Fig. 4a).

\section{TMP prevented As-induced HO-1 activation} through inhibiting the activation of MAPKs/AP-1 pathways

Transcription factor AP-1 interacts with the corresponding binding site in the HO-1 gene promoter region and mediates HO-1 expression (Zhang et al. 2006). Furthermore, members of the MAPK family (ERK, JNK and p38)

(a)

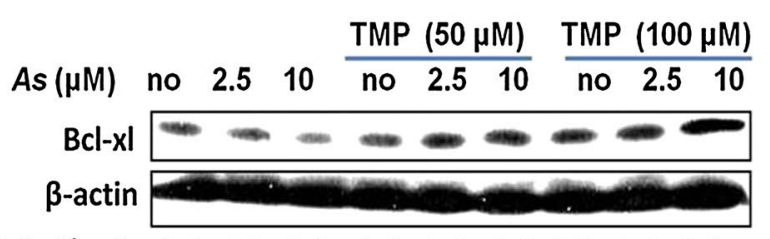

Bcl-xl/actin $0.5 \quad 0.3 \quad 0.2 \quad 0.5 \quad 0.6 \quad 0.6 \quad 0.5 \quad 0.6 \quad 0.8$

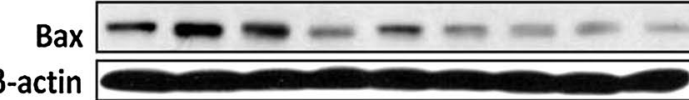

Bax/actin $0.4 \quad 0.9 \quad 0.9 \quad 0.4 \quad 0.5 \quad 0.4 \quad 0.4 \quad 0.3 \quad 0.3$

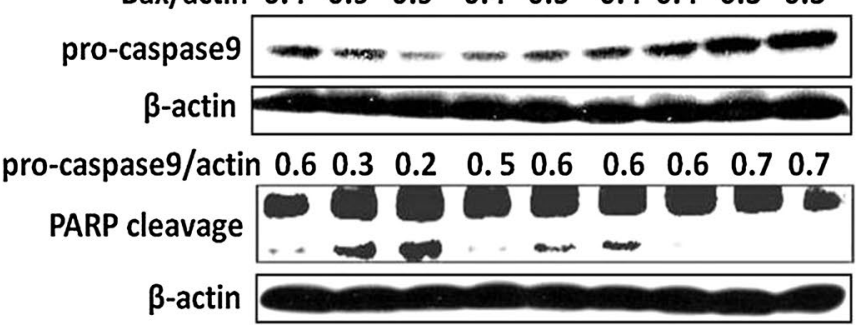

Fig. 4 TMP prevented arsenic-triggered activations of the intrinsic apoptotic pathway and ERK pathway in HK-2 cells. a As treatment $(24 \mathrm{~h})$ increased protein levels of pro-apoptotic Bax and pro-caspase- 9 expressions and decreased levels of anti-apoptotic Bcl-xl, and PARP cleavage, while TMP (50 and $100 \mu \mathrm{M})$ pretreatment prevented contributed to activation of AP-1 (Mossman et al. 2006). Thus, we next monitored impact of As on the activation of MAPK family and AP-1 in HK-2 cells. As shown in Fig. 4b and Fig. 5a, b, As treatment induced MAPK activation (the ERK, JNK and p38 MAPK) $3 \mathrm{~h}$ after treatment in a dosedependent manner. However, individual members showed different dynamic changes. Phospho -JNK peaked at $3 \mathrm{~h}$ and showed the fastest down-regulation, phospho-ERK and phospho-p38 MAPK peaked at $6 \mathrm{~h}$. Up-regulation of phospho-p38 MAPK was very durable and continued until 24 h. TMP co-treatment was very effective against Asinduced ERK and MAPK p38 activation, but demonstrated only modest effects against JNK activation (Figs. 4b, 5a, b). Meanwhile, as an important member of AP-1 family, nuclear phospho-c-Jun protein expression increased after As exposure in a dose-dependent manner, while both 50 and $100 \mu \mathrm{M}$ TMP efficiently inhibited As-induced phospho-c-Jun up-regulation; $100 \mu \mathrm{M}$ TMP demonstrated higher efficiency (Fig. 5c, d).

To further confirm a role of MAPKs in As-induced HO-1 expression, small molecule inhibitors of JNK, ERK and p38 MAPK were used. As shown in Fig. 6a-c, SB203580 (10 $\mu \mathrm{M})$, an inhibitor of MAPK p38, and SP600125 (10 $\mu \mathrm{M})$, a JNK inhibitor, efficiently downregulated HO-1 protein expression induced by 3-h As exposure, while pretreatment with ERK inhibitor U0126 (10 $\mu \mathrm{M})$ did not affect As-induced HO-1 expression, demonstrating the critical roles for MAPK p38 and JNK in

(b)

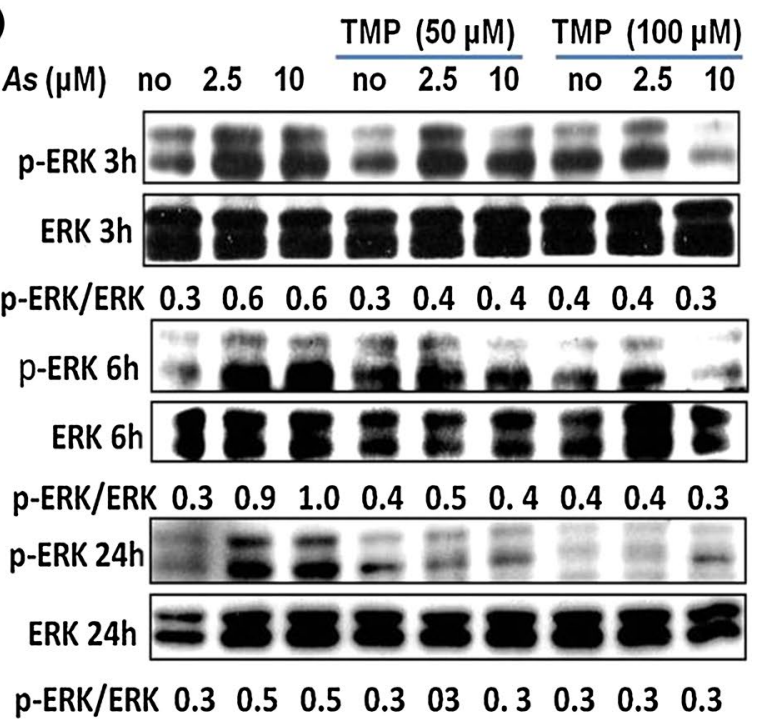

As-triggered the intrinsic apoptotic pathway activation. b As-induced ERK activation was verified by increased level of phospho-Thr202/ Tyr204 ERK (p-ERK) expression, which was inhibited by TMP pretreatment. $\beta$-actin was used as loading control. Values are mean $\pm \mathrm{SD}$ $(n=3)$ 
(a)

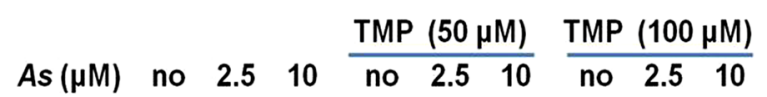

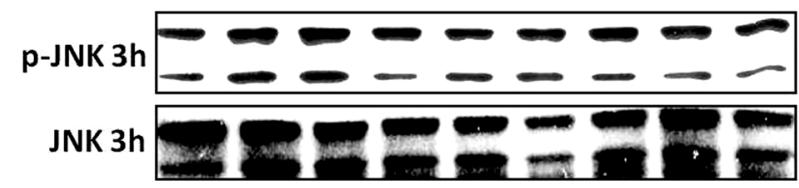

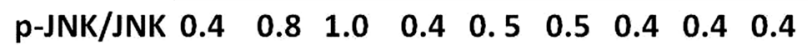
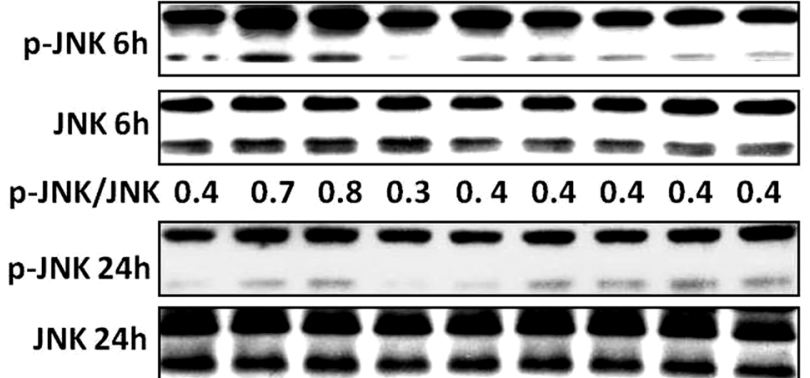

$\begin{array}{llllllllll}\text { p-JNK/JNK } & 0.3 & 0.4 & 0.4 & 0.3 & 0.3 & 0.4 & 0.3 & 0.3 & 0.3\end{array}$

(c)

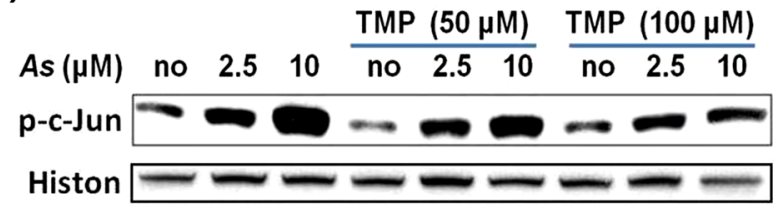

Fig. 5 TMP prevented arsenic-triggered activations of p38 MAPK, JNK and c-Jun pathways in HK-2 cells. As-induced JNK (a) and p38 MAPK (b) activations were verified by increased levels of phosphoThr183/Tyr185 MAPK (p-JNK) and phospho-Thr180/Tyr182 p38 MAPK (p-p38) expression, respectively, which were inhibited by TMP pretreatment. $\mathbf{c}$ and $\mathbf{d}$ 6-h As exposure resulted in nuclear phos-

As-induced induction of HO-1 protein expression. Meanwhile, both 50 and $100 \mu \mathrm{M}$ TMP effectively inhibited As-induced MAPK activation, and compared with 50, and $100 \mu \mathrm{M}$ TMP showed more efficient in inhibiting MAPK activation (Figs. 4b, 5a, b).

TMP prevented As-induced HO-1 through inhibiting the activation of Nrf2 and NF- $\mathrm{B}$ pathways

Two additional transcription factors, Nrf2 and NF- $\mathrm{BB}$, control HO-1 gene and protein expression (Garnier et al. 2013; Wang et al. 2012; Lim et al. 2014). We monitored Nrf2 and phospho-NF-кB p65 (active form) nuclear protein levels after As exposure of HK-2 cells. As shown in Fig. 6e, the nuclear Nrf2 protein was up-regulated in a dose-dependent manner as early as $3 \mathrm{~h}$ after As exposure and peaked at $6 \mathrm{~h}$, while the increased expression lasted to $24 \mathrm{~h}$. A similar dynamics was previously observed for nuclear (b)

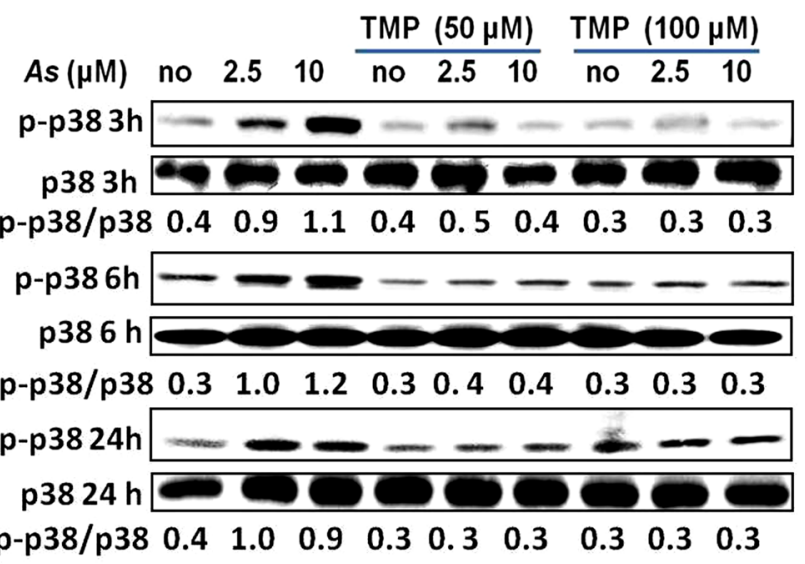

(d)

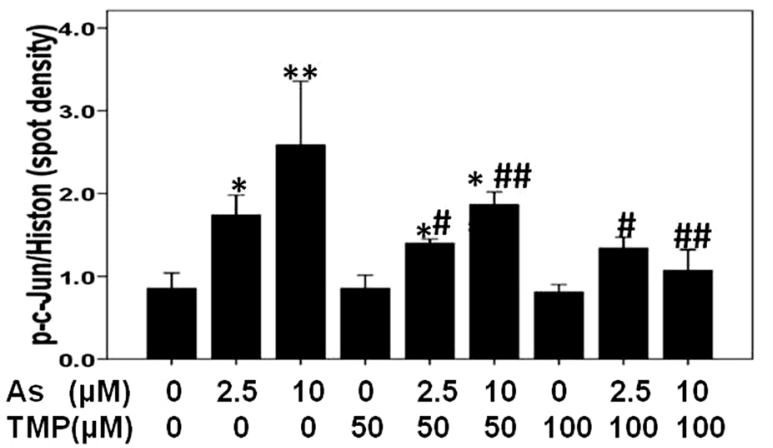

pho-c-Jun up-regulation, while both 50 and $100 \mu \mathrm{M}$ TMP efficiently inhibited As-induced nuclear c-Jun activation. Histone H3 (Histon) and $\beta$-actin were used as loading controls for nuclear and total proteins, respectively. Values are mean $\pm \mathrm{SD}(n=3) ;(*) p<0.05$ versus Con; $\left({ }^{* *}\right) p<0.01$ versus Con; $\left(^{\#}\right) p<0.05$ versus $2.5 \mu \mathrm{M} \mathrm{As,}\left({ }^{\#}\right)$ $p<0.01$ versus $10 \mu \mathrm{M}$ As

phospho-NF-кB expression (Gong et al. 2014). To gain further insight into the relationship between activation of NF- $\kappa$ B p 65 and HO-1 up-regulation induced by As exposure, we used co-treatment with Bay11-7082, an inhibitor of NF- $\mathrm{B}$, which selectively and irreversibly inhibits the inducible phosphorylation of IкB- $\alpha$. As shown in Fig. 6d, As-induced HO-1 protein expression was strongly downregulated by $5 \mu \mathrm{M}$ Bay11-7082. On the other hand, cotreatment with TMP partially suppressed As-induced Nrf2 up-regulation (Fig. 6e). The similar effects of TMP on NF- $\kappa \mathrm{B}$ activation were previously observed (Gong et al. 2014).

TMP prevented As-induced up-regulation of ARS2 expression in HK-2 cells

To elucidate a role of transcription factor ARS2 in arsenicinduced kidney injury, we determined As-induced protein 
(a)
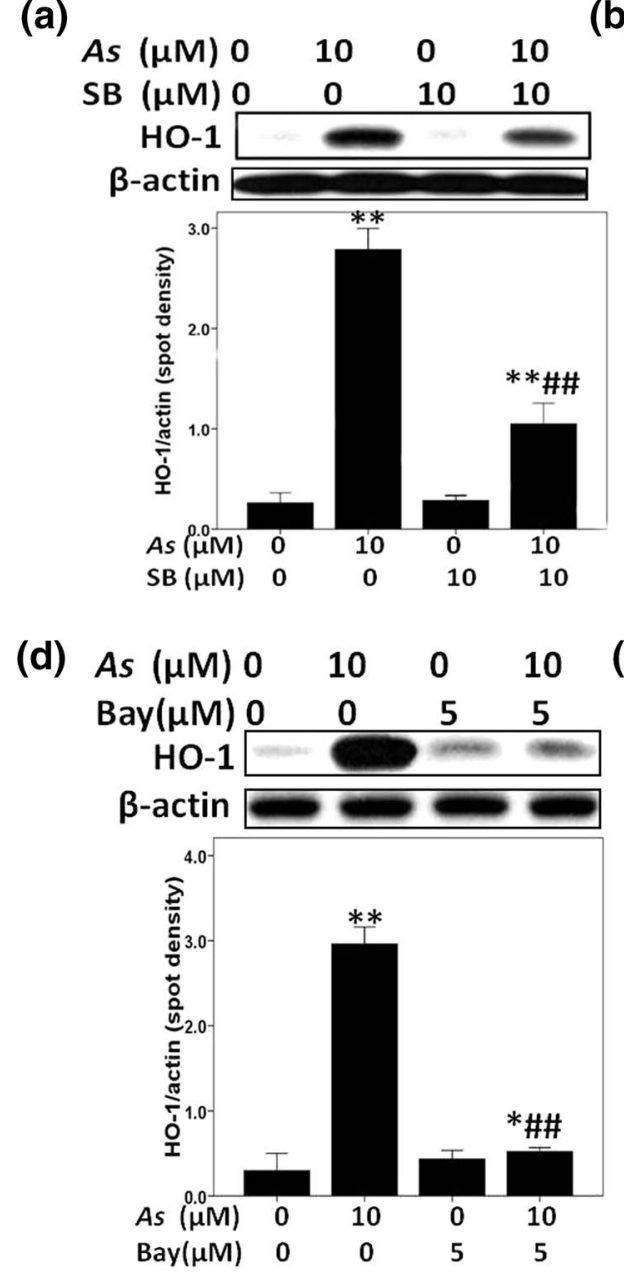

(b)
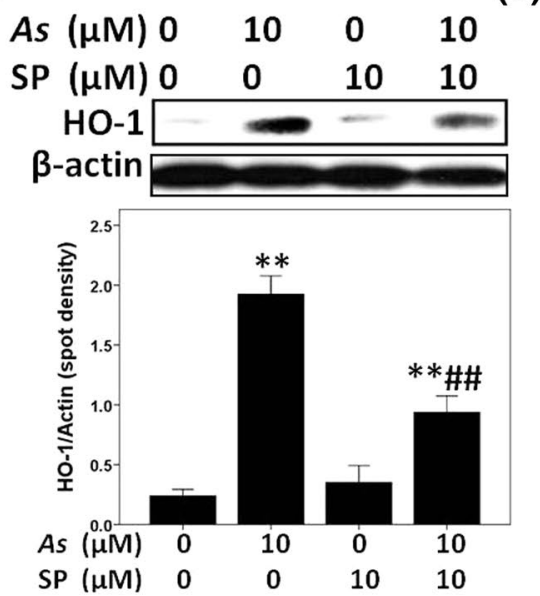

(c)

\begin{tabular}{|c|c|c|c|c|}
\hline$(\mu \mathrm{M})$ & & 10 & 0 & 10 \\
\hline Uo $(\mu \mathrm{M})$ & 10 & 0 & 10 & 10 \\
\hline HO-1 & - & & $=$ & \\
\hline
\end{tabular}

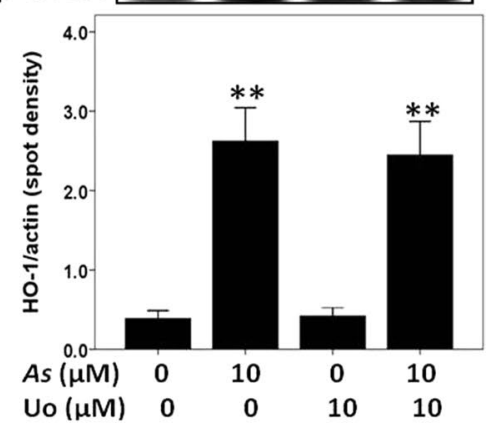

(e)

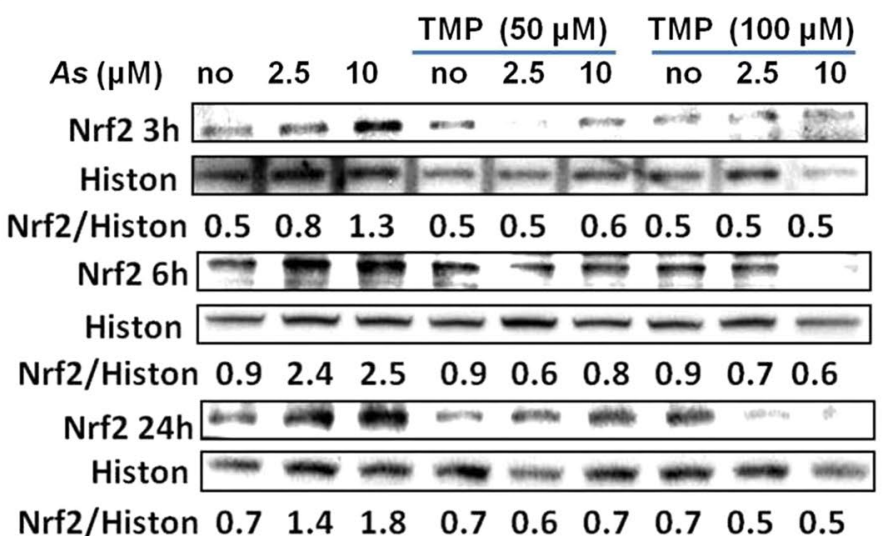

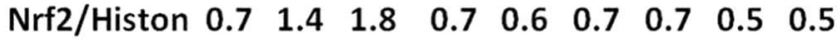

Fig. 6 TMP prevented arsenic-triggered activation of Nrf2 pathway in HK-2 cells; meanwhile, arsenic-induced HO-1 was Nrf2, NF-кB, p38 MAPK and JNK dependent. SB203580 (SB) (a), SP600125 (SP) (b) and Bay11-7082 (Bay) (d), not UO126 (UO) (c), inhibited arsenic-induced HO-1 expressions in HK-2 cells. Additionally, TMP

expression of ARS2 in HK-2 cells. As shown in Fig. 7a, As treatment increased ARS2 protein expression, and such an up-regulation was peaking at $6 \mathrm{~h}$ and then gradually decreased. TMP $(100 \mu \mathrm{M})$ efficiently inhibited As-induced ARS2 up-regulation. Next, to achieve the purpose whether MAPKs and NF- $\kappa \mathrm{B}$ contributed to As-mediated ARS2 induction, we used co-treatment with As and specific molecule inhibitors. SB203580 (an inhibitor of p38) and U0126 (an inhibitor of ERK), but not SP600125 (an inhibitor of JNK), obviously inhibited As-induced ARS2 up-regulation at $6 \mathrm{~h}$, which indicated MAPK p38 and ERK acted at the upstream of ARS2 expression (Fig. 7c-e). Additionally, as Fig. 7b demonstrates, Bay11-7082 reversed the effect of As on ARS2, which indicated that As-induced ARS2 up-regulation was also modulated by NF- $\mathrm{B}$ activation in $\mathrm{HK}-2$ cells. inhibited arsenic-induced up-regulation of nuclear Nrf2 in HK-2 cells (e). Histone $\mathrm{H} 3$ (Histon) and $\beta$-actin were used as loading controls for nuclear and total proteins, respectively. Values are mean $\pm \mathrm{SD}$ $(n=3),(*) p<0.05$ versus Con; $(* *) p<0.01$ versus Con; $\left(^{\# \#}\right)$ $p<0.01$ versus $10 \mu \mathrm{M}$ As

\section{Discussion}

Our previous study (Gong et al. 2014) identified that sodium arsenite at a clinically relevant dose also might be a risk factor for kidney, while TMP could prevent such an As-induced nephrotoxicity by reducing ROS production, preventing mitochondria dysfunction and suppressing activation of pro-inflammatory signals, including $\beta$-catenin, NF- $\kappa \mathrm{B}, \mathrm{TNF}-\alpha$ and cyclooxygenase-2 (COX2). However, the precise renal cellular adaptive mechanism and antioxidant-mediated protective responses against arsenic exposure with clinically relevant dose are still not clear. In the present study, we revealed that clinically relevant concentrations of sodium arsenite induced dose-dependent and specific activation of MAPKs that further activated 
(a)

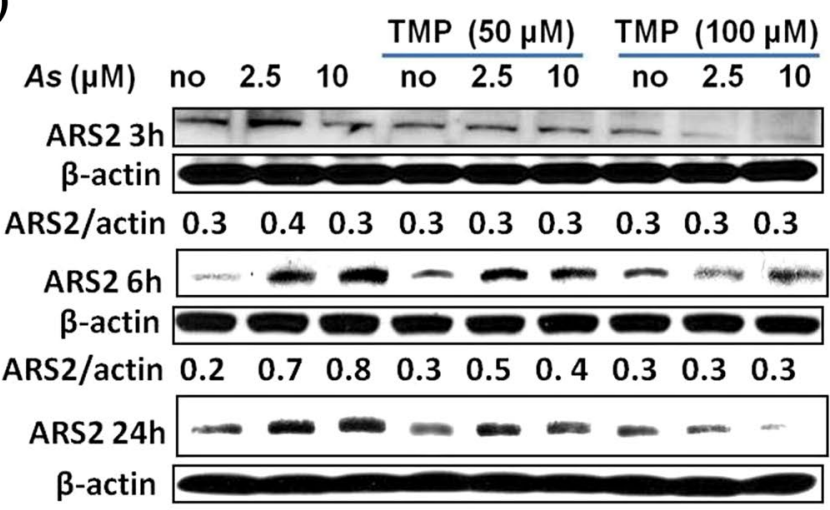

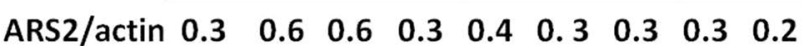

(b)

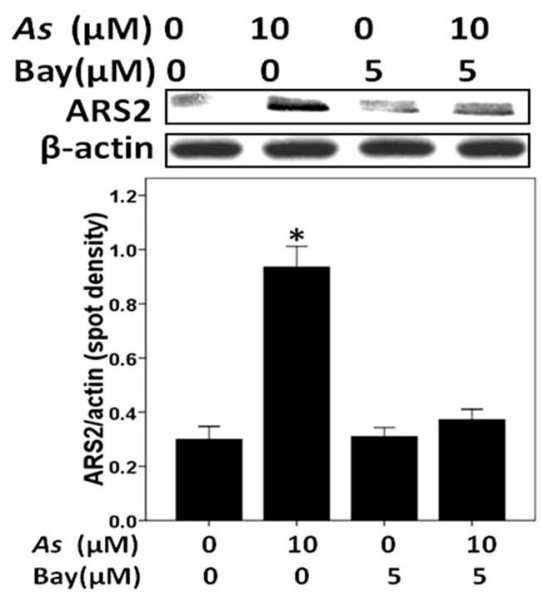

(e)

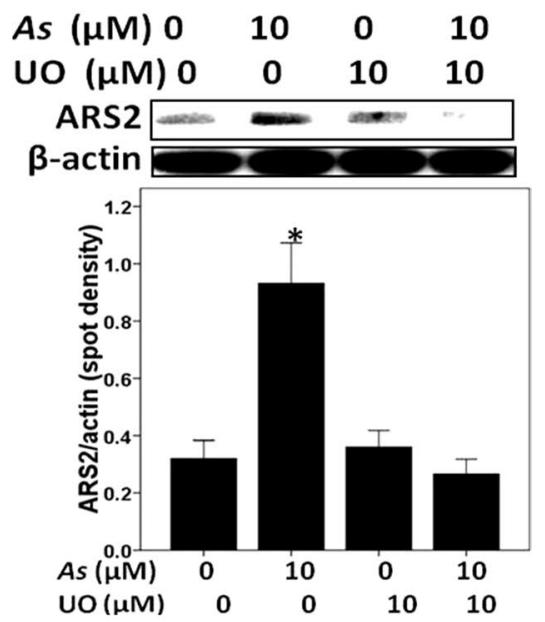

Fig. 7 Arsenic-triggered ARS2 expression was NF-кB, p38 MAPK and ERK dependent in HK-2 cells. Pretreatment of TMP (a), Bay117082 (Bay) (b), SB203580 (SB) (c) and UO126 (UO) (e), while not

transcription factors Nrf2, NF-кB and AP-1/c-Jun, which then control the downstream antioxidant response of HO-1 in HK-2 cells. Additionally, we observed the up-regulation of transcription factor ARS2 expression in this processes, which strongly supported the previous speculation about essential function of ARS2 (Wilson et al. 2008). Interestingly, TMP inhibited As-induced Nrf2, AP-1 and MAPK family activations, accordingly, and reduced HO-1 and ARS2 expressions, which might contribute to its nephroprotective effects.

HO-1 has been identified as a biological hallmark of cells in response to unfavorable environment, including oxidative stress (Teng et al. 2013; Lee et al. 2012). In our previous study (Gong et al. 2014), As exposure dramatically increased cellular ROS production in HK-2 cells, and antioxidant NAC and TMP efficiently prevented Asinduced cytotoxicity and ROS production. In the present study, the involvement of oxidative stress in As-induced
SP600125 (SP) (d), efficiently inhibited As-induced ARS2 expression. $\beta$-actin was used as loading control for total proteins. Values are mean $\pm \mathrm{SD}(n=3),(*) p<0.05$ versus Con

nephrotoxicity was further investigated by monitoring HO-1 expression. As shown in Fig. 1a, b, we identified the induced HO-1 protein expression after As exposure was in a dose- and time-dependent manner, whereas the treatment of TMP and antioxidant NAC blocked As-induced HO-1 expression. Such a result also suggested the tight relationship between HO-1 induction and intracellular ROS production after arsenite exposure in HK-2 cells. Interestingly, aminoguanidine (AG), the inhibitor of iNOS, has no effect on the expression of HO-1 in response to As, which suggested that As-induced HO-1 production might mainly be mediated by ROS, not nitrosative stress.

Furthermore, a role of HO-1 in As-induced nephrotoxicity was investigated using ZnPP, a known inhibitor of HO-1. Blocking As-induced HO-1 enzymatic activity by $\mathrm{ZnPP}$ resulted in decreased cell viability (data not shown) and promoted As-induced programmed cell death ascertained by increased sub-G1 phase and TUNEL-positive 
cells. Accordingly, cellular ROS production achieved 5.35fold increasing, significantly higher than after As treatment. Our previous data have confirmed that mitochondrial damage was involved in As-induced nephrotoxicity (Gong et al. 2014). In the present study, we found that blocking HO-1 further exacerbated As-induced mitochondrial injury and respiratory chain damage, ascertained as a decrease in the number of tubular mitochondria and down-regulation in Cox expression. All these data mentioned above strongly demonstrated that HO-1 played a protective role in Asinduced nephrotoxicity, and blocking HO-1 augmented As-induced cell death, ROS production and mitochondrial injury. In the other studies, HO-1 also has been shown to protect kidney against several acute kidney injury (AKI) (Billings et al. 2014; Miyagi et al. 2014; Goodman et al. 2007).

Nuclear factor erythroid derived-2 (Nrf2) is involved in one of the most important cellular defense mechanisms against oxidative stress by regulating cytoprotective enzymes expressions, for example, HO-1 (Zhang et al. 2012; Kilic et al. 2013). Furthermore, Nrf2 has been viewed as a protective protein against genotoxic damage. Consistent with the above views, there is evidence that Nrf2 could protect human bladder urothelial cells (Wang et al. 2007) from As toxicity and attenuate hyperglycemiainduced kidney injury in diabetic mice (Li et al. 2011). In contrast, the present study demonstrated that Nrf2 and Nrf2-regulated cytoprotective HO-1 genes were activated after As exposure at a clinically relevant dose, and such an increased expression of Nrf2 and HO-1 failed to rescue HK-2 cells from As-induced cytotoxicity. Similar results were observed in As-treated oral squamous cells, which might suggest that Nrf2- and HO-1-dependent protection was overwhelmed by As cytotoxicity (Zhang et al. 2012). Indeed, while up-regulation of HO-1 is regarded as cytoprotective under various experiment conditions, it can be non-sufficient to fully recover cells from oxidative damage, as shown in our study and other publication (Wang et al. 2012).

Although many studies highlighted the importance of Nrf2 pathway in As-induced HO-1 expression in different cell lines ( $\mathrm{Li}$ et al. 2013; Pi et al. 2008), indeed, the mechanisms underlying HO-1 induction are regulated by the complex signaling network. In the present study, we observed a discrepancy between Nrf2 and HO-1 protein expression after As exposure in HK-2 cells: As-induced HO-1 expression was in a dose- and time-dependent manner, whereas As-induced Nrf2 expression peaked at $6 \mathrm{~h}$ and then degraded gradually. Such discrepancy also suggested that As might induce HO-1 gene expression through Nrf2independent pathways. The previous research suggested that Nrf2 played essential role for HO-1 induction only in the early and transient phase after As exposure in embryonic fibroblasts ( $\mathrm{Li}$ et al. 2013).

HO-1 induction is tightly regulated primarily at the transcriptional level, Nrf2 recruited BRG1 to the HO-1 enhancers and the promoter, meanwhile, activator protein-1 (AP-1) and NF-кB located in HO-1 gene promoter region (Zhang et al. 2006). Our previous data identified that As with clinical dose induced phospho-NF- $\kappa \mathrm{B}$ p65 nuclear protein (active form) expression in HK-2 cells (Gong et al. 2014). In the present study, to gain insight into the functional relationship between NF- $\mathrm{KB}$ activation and HO-1 up-regulation in response to As, HK-2 cells were preincubated with Bay11-7082, a specific inhibitor of NF-kB, for $30 \mathrm{~min}$ followed by $10 \mu \mathrm{M}$ sodium arsenite treatment for $6 \mathrm{~h}$. Figure $6 \mathrm{~b}$ shows co-treatment of $10 \mu \mathrm{M}$ sodium arsenite and Bay substantially inhibited HO-1 expression as compared with As alone, which further indicated that the induction of HO-1 expression in As-induced nephrotoxicity is through multiple pathways and, at least partially, through NF- $\kappa \mathrm{B}$ activation.

AP-1 is another transcription factor that could control the HO-1 gene expression (Zhang et al. 2006). In addition, MAPKs contributed to AP-1 induction (Hsieh et al. 2014). Thus, we next monitored As impact on the activations of MAPKs and AP-1 and investigated the relationship between MAPKs and HO-1 expression in HK-2 cells. As shown in Figs. 4b and 5, arsenic exposure resulted in MAPK family activations, which is very consistent to the other studies (Wang et al. 2012; Kang et al. 2003), but such activation seemed to be cell and species dependent (Wang et al. 2012). For example, As exposure only strongly activated p38 MAPK in normal human lung fibroblast and did not activate ERK and JNK (Wang et al. 2013a).

Additionally, the present study established that arsenic exposure within clinically relevant dose could activate AP-1 family member c-Jun in HK-2 cells (Fig. 5c, d) that is very consistent to the previous study (Deshane et al. 2010) demonstrating its role for HO-1 induction in renal epithelial cell. Interestingly, only SB203580 (an inhibitor of p38) and SP600125 (an inhibitor of JNK), but not U0126 (an inhibitor of ERK), efficiently attenuated As-induced HO-1 production that confirmed only p38 MAPK and JNK, but not ERK, contributed to the up-regulation of HO-1 after As exposure in HK2 cells.

Taken together, our present data demonstrated that the regulation mechanisms of As-induced HO-1 expression were performed through multiple signal pathways, Nrf2, NF- $\mathrm{BB}, \mathrm{AP}-1, \mathrm{p} 38$ MAPK and JNK.

In our previous study, TMP could reverse the Asinduced sequence of pro-inflammatory signal regulators, including NF- $\mathrm{kB}$, p38 MAPK, beta-catenin and COX2, and protect HK-2 cells against As-induced programmed cell 
death (autophagy and apoptosis) (Gong et al. 2014). In current study, another novel finding is the demonstration that TMP could also suppress the activations of Nrf2, AP-1, JNK and ERK after As exposure, accordingly, block HO-1 protein expression in HK-2 cells. Furthermore, such protection was performed by preventing As-triggered activation of the intrinsic apoptotic pathway. Interestingly, TMP was also found to inhibit proliferation of human promyelocytic leukemia cell line HL-60 (Wu et al. 2012).

So far, there were no related reports, which focused on the effects of As on induction of transcription factor ARS2 in As-induced nephrotoxicity. In the present study, As treatment increased ARS2 protein expression. Interestingly, the dynamic change in As-induced ARS2 expression showed a similar manner with COX2 (Gong et al. 2014). Similar to the effects on MAPKs, TMP efficiently inhibited ARS2 up-regulation. Nevertheless, attention should be paid to the very interesting phenomenon, demonstrating that Bay11-7082 (a specific inhibitor of NF-kB), SB203580 (an inhibitor of p38) and U0126 (an inhibitor of ERK), but not SP600125 (an inhibitor of JNK), attenuate the effects of As on ARS2 expression. This indicated that As-induced ARS2 up-regulation was modulated by the activations of NF- $\mathrm{KB}$, p38 MAPK and ERK, but not JNK in HK-2 cells. To our knowledge, this is the first report demonstrating that ARS2 involved in As-induced nephrotoxicity and it was regulated by p38 MAPK, ERK and NF- $\kappa$ B. Further studies focusing on the potential function of ARS2 in As-induced nephrotoxicity is worthy of attention.

Although it is not clear which role ARS2 plays in Asinduced nephrotoxicity, but given ARS2 and HO-1 sharing the similar regulation mechanism, we thus hypothesize that ARS2 and HO-1 might mediate cell survival in response to As treatment in HK-2 cells. Previous report also has revealed that ARS2 played a role in RNA interference regulation during cell proliferation and in the ability of mammalian cells to proliferate (Gruber et al. 2009) that also gave the supporting evidence for our speculation of ARS2 mediating cell survival in As-induced nephrotoxicity in HK-2 cells.

In summary, the present study further confirmed that arsenic treatment at clinically relevant dose results in renal damage, additionally, the activations of Nrf2, AP-1, MAPK family and ARS2 involved in such a nephrotoxicity. Furthermore, the cytoprotective HO-1 induction after As exposure in HK-2 cells is mediated by multiple pathways, including Nrf2, NF-кB, AP-1, p38 MAPK and JNK. The current data also demonstrated TMP efficiently reverses As-induced Nrf2, NF- $\mathrm{B}, \mathrm{AP}-1$, MAPK family activations and blocks the according HO-1 and ARS2 expressions. Although further studies are required, we can still propose TMP could be effective in the treatment of arsenic-induced nephrotoxicity.
Acknowledgments The authors would like to thank Drs. Preety Sharma, Erik Young, Bo Zhang, Gangkun Lin, Wupeng Liao, Hongning Zhou and Winsome Walker for advice and helpful discussion. This work was supported by Environmental Center Grant P30 ES009089, NIH Grant P01 CA049062 and National Natural Science Foundation of China Grant 81573936 and 81373614.

\section{Compliance with ethical standards}

Conflict of interest The authors declare that they have no conflict of interest.

\section{References}

Andreu-Agullo C, Maurin T, Thompson CB, Lai EC (2012) Ars2 maintains neural stem-cell identity through direct transcriptional activation of Sox2. Nature 481(7380):195-198. doi:10.1038/ nature 10712

Billings IF, Yu C, Byrne JG, Petracek MR, Pretorius M (2014) Heme oxygenase-1 and acute kidney injury following cardiac surgery. Cardiorenal Med 4(1):12-21. doi:10.1159/000357871

Chang CF, Liu XM, Peyton KJ, Durante W (2014) Heme oxygenase- 1 counteracts contrast media-induced endothelial cell dysfunction. Biochem Pharmacol 87(2):303-311. doi:10.1016/j. bcp.2013.11.002

Chen JW, Chen HY, Li WF, Liou SH, Chen CJ, Wu JH, Wang SL (2011) The association between total urinary arsenic concentration and renal dysfunction in a community-based population from central Taiwan. Chemosphere 84(1):17-24. doi:10.1016/j. chemosphere.2011.02.091

Chen WJ, Huang YL, Shiue HS, Chen TW, Lin YF, Huang CY, Lin YC, Han BC, Hsueh YM (2014) Renin-angiotensin-aldosterone system related gene polymorphisms and urinary total arsenic is related to chronic kidney disease. Toxicol Appl Pharmacol 279(2):95-102. doi:10.1016/j.taap.2014.05.011

Deshane J, Kim J, Bolisetty S, Hock TD, Hill-Kapturczak N, Agarwal A (2010) Sp1 regulates chromatin looping between an intronic enhancer and distal promoter of the human heme oxygenase-1 gene in renal cells. J Biol Chem 285(22):16476-16486. doi:10.1074/jbc.M109.058586

Fan SF, Chao PL, Lin AM (2010) Arsenite induces oxidative injury in rat brain: synergistic effect of iron. Ann N Y Acad Sci 1199:2735. doi:10.1111/j.1749-6632.2009.05170.x

Garnier N, Petruccelli LA, Molina MF, Kourelis M, Kwan S, Diaz Z, Schipper HM, Gupta A, del Rincon SV, Mann KK, Miller WH Jr (2013) The novel arsenical Darinaparsin circumvents BRG1dependent, HO-1-mediated cytoprotection in leukemic cells. Leukemia 27(11):2220-2228. doi:10.1038/leu.2013.54

Gong X, Celsi G, Carlsson K, Norgren S, Chen M (2010) N-acetylcysteine amide protects renal proximal tubular epithelial cells against iohexol-induced apoptosis by blocking p38 MAPK and iNOS signaling. Am J Nephrol 31(2):178-188. doi: $10.1159 / 000268161$

Gong X, Ivanov VN, Davidson MM, Hei TK (2014) Tetramethylpyrazine (TMP) protects against sodium arsenite-induced nephrotoxicity by suppressing ROS production, mitochondrial dysfunction, pro-inflammatory signaling pathways and programed cell death. Arch Toxicol. doi:10.1007/s00204-014-1302-y

Goodman AI, Olszanecki R, Yang LM, Quan S, Li M, Omura S, Stec DE, Abraham NG (2007) Heme oxygenase-1 protects against radiocontrast-induced acute kidney injury by regulating anti-apoptotic proteins. Kidney Int 72(8):945-953. doi:10.1038/sj.ki.5002447

Gruber JJ, Zatechka DS, Sabin LR, Yong J, Lum JJ, Kong M, Zong WX, Zhang Z, Lau CK, Rawlings J, Cherry S, Ihle JN, Dreyfuss 
G, Thompson CB (2009) Ars2 links the nuclear cap-binding complex to RNA interference and cell proliferation. Cell 138(2):328-339. doi:10.1016/j.cell.2009.04.046

Hsieh HL, Lin CC, Chan HJ, Yang CM (2014) c-Src-dependent EGF receptor transactivation contributes to ET-1-induced COX-2 expression in brain microvascular endothelial cells. J Neuroinflamm 9:152. doi:10.1186/1742-2094-9-152

Huang JX, Kaeslin G, Ranall MV, Blaskovich MA, Becker B, Butler MS, Little MH, Lash LH, Cooper MA (2015) Evaluation of biomarkers for in vitro prediction of drug-induced nephrotoxicity: comparison of HK-2, immortalized human proximal tubule epithelial, and primary cultures of human proximal tubular cells. Pharmacol Res Perspect 3(3):e00148. doi:10.1002/prp2.148

Ivanov VN, Hei TK (2004) Arsenite sensitizes human melanomas to apoptosis via tumor necrosis factor alpha-mediated pathway. J Biol Chem 279(21):22747-22758. doi:10.1074/jbc.M314131200

Ivanov VN, Hei TK (2005) Combined treatment with EGFR inhibitors and arsenite upregulated apoptosis in human EGFR-positive melanomas: a role of suppression of the PI3K-AKT pathway. Oncogene 24(4):616-626. doi:10.1038/sj.onc.1208125

Ivanov VN, Hei TK (2013) Induction of apoptotic death and retardation of neuronal differentiation of human neural stem cells by sodium arsenite treatment. Exp Cell Res 319(6):875-887. doi:10.1016/j.yexcr.2012.11.019

Kang SH, Song JH, Kang HK, Kang JH, Kim SJ, Kang HW, Lee YK, Park DB (2003) Arsenic trioxide-induced apoptosis is independent of stress-responsive signaling pathways but sensitive to inhibition of inducible nitric oxide synthase in HepG2 cells. Exp Mol Med 35(2):83-90. doi:10.1038/emm.2003.12

Kilic U, Kilic E, Tuzcu Z, Tuzcu M, Ozercan IH, Yilmaz O, Sahin F, Sahin K (2013) Melatonin suppresses cisplatin-induced nephrotoxicity via activation of Nrf-2/HO-1 pathway. Nutr Metab (Lond) 10(1):7. doi:10.1186/1743-7075-10-7

Kiriyama M, Kobayashi Y, Saito M, Ishikawa F, Yonehara S (2009) Interaction of FLASH with arsenite resistance protein 2 is involved in cell cycle progression at $\mathrm{S}$ phase. Mol Cell Biol 29(17):4729-4741. doi:10.1128/MCB.00289-09

Lee JE, Park JH, Shin IC, Koh HC (2012) Reactive oxygen species regulated mitochondria-mediated apoptosis in PC12 cells exposed to chlorpyrifos. Toxicol Appl Pharmacol 263(2):148 162. doi:10.1016/j.taap.2012.06.005

Li H, Zhang L, Wang F, Shi Y, Ren Y, Liu Q, Cao Y, Duan H (2011) Attenuation of glomerular injury in diabetic mice with tertbutylhydroquinone through nuclear factor erythroid 2-related factor 2-dependent antioxidant gene activation. Am J Nephrol 33(4):289-297. doi:10.1159/000324694

Li B, Li X, Zhu B, Zhang X, Wang Y, Xu Y, Wang H, Hou Y, Zheng Q, Sun G (2013) Sodium arsenite induced reactive oxygen species generation, nuclear factor (erythroid-2 related) factor 2 activation, heme oxygenase- 1 expression, and glutathione elevation in Chang human hepatocytes. Environ Toxicol 28(7):401-410. doi:10.1002/tox.20731

Lim JL, Wilhelmus MM, de Vries HE, Drukarch B, Hoozemans JJ, van Horssen J (2014) Antioxidative defense mechanisms controlled by Nrf2: state-of-the-art and clinical perspectives in neurodegenerative diseases. Arch Toxicol 88(10):1773-1786. doi:10.1007/s00204-014-1338-z

Michael HA (2013) Geochemistry. An arsenic forecast for China. Science 341(6148):852-853. doi:10.1126/science.1242212

Miyagi MY, Seelaender M, Castoldi A, de Almeida DC, Bacurau AV, Andrade-Oliveira V, Enjiu LM, Pisciottano M, Hayashida CY, Hiyane MI, Brum PC, Camara NO, Amano MT (2014) Longterm aerobic exercise protects against cisplatin-induced nephrotoxicity by modulating the expression of IL-6 and HO-1. PLoS ONE 9(10):e108543. doi:10.1371/journal.pone.0108543
Mossman BT, Lounsbury KM, Reddy SP (2006) Oxidants and signaling by mitogen-activated protein kinases in lung epithelium. Am J Respir Cell Mol Biol 34(6):666-669. doi:10.1165/ rcmb.2006-0047SF

Peraza MA, Carter DE, Gandolfi AJ (2003) Toxicity and metabolism of subcytotoxic inorganic arsenic in human renal proximal tubule epithelial cells (HK-2). Cell Biol Toxicol 19(4):253-264

Peraza MA, Cromey DW, Carolus B, Carter DE, Gandolfi AJ (2006) Morphological and functional alterations in human proximal tubular cell line induced by low level inorganic arsenic: evidence for targeting of mitochondria and initiated apoptosis. J Appl Toxicol 26(4):356-367. doi:10.1002/jat.1149

Pi J, Diwan BA, Sun Y, Liu J, Qu W, He Y, Styblo M, Waalkes MP (2008) Arsenic-induced malignant transformation of human keratinocytes: involvement of Nrf2. Free Radic Biol Med 45(5):651-658. doi:10.1016/j.freeradbiomed.2008.05.020

Rodriguez-Lado L, Sun G, Berg M, Zhang Q, Xue H, Zheng Q, Johnson CA (2013) Groundwater arsenic contamination throughout China. Science 341(6148):866-868. doi:10.1126/ science. 1237484

Rossman TG, Wang Z (1999) Expression cloning for arsenite-resistance resulted in isolation of tumor-suppressor fau cDNA: possible involvement of the ubiquitin system in arsenic carcinogenesis. Carcinogenesis 20(2):311-316

Ruiz-Hernandez A, Kuo CC, Rentero-Garrido P, Tang WY, Redon J, Ordovas JM, Navas-Acien A, Tellez-Plaza M (2015) Environmental chemicals and DNA methylation in adults: a systematic review of the epidemiologic evidence. Clin Epigenetics 7(1):55. doi:10.1186/s13148-015-0055-7

Schreiber E, Matthias P, Muller MM, Schaffner W (1989) Rapid detection of octamer binding proteins with 'mini-extracts', prepared from a small number of cells. Nucleic Acids Res 17(15):6419

Shen ZX, Chen GQ, Ni JH, Li XS, Xiong SM, Qiu QY, Zhu J, Tang W, Sun GL, Yang KQ, Chen Y, Zhou L, Fang ZW, Wang YT, Ma J, Zhang P, Zhang TD, Chen SJ, Chen Z, Wang ZY (1997) Use of arsenic trioxide (As2O3) in the treatment of acute promyelocytic leukemia (APL): II. Clinical efficacy and pharmacokinetics in relapsed patients. Blood 89(9):3354-3360

Teng YC, Tai YI, Lee YH, Lin AM (2013) Role of HO-1 in the arsenite-induced neurotoxicity in primary cultured cortical neurons. Mol Neurobiol 48(2):281-287. doi:10.1007/s12035-013-8492-9

Wang J, Dore S (2007) Heme oxygenase-1 exacerbates early brain injury after intracerebral haemorrhage. Brain 130(Pt 6): $1643-1652$

Wang XJ, Sun Z, Chen W, Eblin KE, Gandolfi JA, Zhang DD (2007) Nrf2 protects human bladder urothelial cells from arsenite and monomethylarsonous acid toxicity. Toxicol Appl Pharmacol 225(2):206-213. doi:10.1016/j.taap.2007.07.016

Wang L, Kou MC, Weng CY, Hu LW, Wang YJ, Wu MJ (2012) Arsenic modulates heme oxygenase-1, interleukin-6, and vascular endothelial growth factor expression in endothelial cells: roles of ROS, NF-kappaB, and MAPK pathways. Arch Toxicol 86(6):879-896. doi:10.1007/s00204-012-0845-z

Wang Q, Wu L, Wang J (2013a) Reciprocal regulation of cyclooxygenase 2 and heme oxygenase 1 upon arsenic trioxide exposure in normal human lung fibroblast. J Biochem Mol Toxicol 27(6):323-329. doi:10.1002/jbt.21491

Wang S, Wei Q, Dong G, Dong Z (2013b) ERK-mediated suppression of cilia in cisplatin-induced tubular cell apoptosis and acute kidney injury. Biochim Biophys Acta 1832(10):1582-1590. doi:10.1016/j.bbadis.2013.05.023

Wilson MD, Wang D, Wagner R, Breyssens H, Gertsenstein M, Lobe C, Lu X, Nagy A, Burke RD, Koop BF, Howard PL (2008) ARS2 is a conserved eukaryotic gene essential for early mammalian 
development. Mol Cell Biol 28(5):1503-1514. doi:10.1128/ MCB.01565-07

Wu Y, Xu Y, Shen Y, Wang C, Guo G, Hu T (2012) Tetramethylpyrazine potentiates arsenic trioxide activity against HL-60 cell lines. Braz J Med Biol Res 45(3):187-196

Yu M, Xue J, Li Y, Zhang W, Ma D, Liu L, Zhang Z (2013) Resveratrol protects against arsenic trioxide-induced nephrotoxicity by facilitating arsenic metabolism and decreasing oxidative stress. Arch Toxicol 87(6):1025-1035. doi:10.1007/s00204-013-1026-4

Zhang J, Ohta T, Maruyama A, Hosoya T, Nishikawa K, Maher JM, Shibahara S, Itoh K, Yamamoto M (2006) BRG1 interacts with $\mathrm{Nrf} 2$ to selectively mediate HO-1 induction in response to oxidative stress. Mol Cell Biol 26(21):7942-7952. doi:10.1128/ MCB.00700-06
Zhang X, Su Y, Zhang M, Sun Z (2012) Opposite effects of arsenic trioxide on the Nrf2 pathway in oral squamous cell carcinoma in vitro and in vivo. Cancer Lett 318(1):93-98. doi:10.1016/j. canlet.2011.12.005

Zheng LY, Umans JG, Tellez-Plaza M, Yeh F, Francesconi KA, Goessler W, Silbergeld EK, Guallar E, Howard BV, Weaver VM, Navas-Acien A (2013) Urine arsenic and prevalent albuminuria: evidence from a population-based study. Am J Kidney Dis 61(3):385-394. doi:10.1053/j.ajkd.2012.09.011

Zheng L, Kuo CC, Fadrowski J, Agnew J, Weaver VM, Navas-Acien A (2014) Arsenic and chronic kidney disease: a systematic review. Curr Environ Health Rep 1(3):192-207. doi:10.1007/ s40572-014-0024-x 